\title{
A NEW APPROACH FOR EVALUATING THE RESISTANCE OF WHEEL STEEL TO SPALL FORMATION
}

\author{
Taras Lenkovskiy $^{1}$ - Artem Glazov ${ }^{2}$ - Volodymyr Kulyk ${ }^{3 *}$ - Zoia Duriagina ${ }^{3,4}$ - Andriy Dzyubyk ${ }^{5}$ \\ Roman Kovalchuk $^{6}$ - Volodymyr Topilnytskyy ${ }^{7}-$ Lyudmyla Dzyubyk $^{8}$ - Volodymyr Vira ${ }^{9}$
}

\begin{abstract}
${ }^{1}$ Department of Strength and Durability of Structures under Complex Loading, Karpenko Physico-Mechanical Institute of the NAS of Ukraine, 5 Naukova St., Lviv 79060, Ukraine

${ }^{2}$ Department of Theoretical Fundamentals of Fracture Mechanics, Karpenko Physico-Mechanical Institute of the NAS of Ukraine, 5 Naukova St., Lviv 79060, Ukraine

${ }^{3}$ Department of Applied Materials Science and Materials Engineering, Institute of Engineering Mechanics and Transport, Lviv Polytechnic National University, 12 Bandera St., Lviv 79013, Ukraine

${ }^{4}$ Department of Physical Chemistry and Physicochemical Fundamentals of Environmental Engineering, Institute of Environmental Engineering, The John Paul II Catholic University of Lublin, 14 Racławickie Al., Lublin 20-950, Poland

${ }^{5}$ Department of Welding Manufacture, Diagnostics and Restoration of Metal Structures, Institute of Engineering Mechanics and Transport, Lviv Polytechnic National University, 12 Bandera St., Lviv, 79013 Ukraine

${ }^{6}$ Department of Engineering Mechanics (Weapons and Equipment of Military Engineering Forces), Faculty of training specialists battle (operational) software, Hetman Petro Sahaidachnyi National Army Academy, 32 Heroes of Maidan St., Lviv 79012, Ukraine

${ }^{7}$ Department of Designing and Operation of Machines, Institute of Engineering Mechanics and Transport, Lviv Polytechnic National University, 12 Bandera St., Lviv, 79013 Ukraine

${ }^{8}$ Department of Machine Parts, Institute of Engineering Mechanics and Transport, Lviv Polytechnic National University, 12 Bandera St., Lviv, 79013 Ukraine

${ }^{9}$ Department of Bridges and Structural Mechanics, Institute of Building and Environmental Engineering, Lviv Polytechnic National University, 12 Bandera St., Lviv, 79013 Ukraine
\end{abstract}

\begin{tabular}{l} 
ARTICLE INFO \\
\hline Article history: \\
Received: 19. 4. 2018. \\
Received in revised form: 21. 10. 2018. \\
Accepted: 7. 11. 2018. \\
\hline Keywords: \\
Wheel steel \\
Fatigue life \\
Rolling contact fatigue \\
Spalling \\
\hline DOI: http://doi.org/10.30765/er.40.2.08 \\
\hline
\end{tabular}

\section{Introduction}

Ensuring long-term operation of structure elements and machine parts at rolling contact fatigue conditions is an important scientific and engineering task [1]. It is known [2-5] that fatigue cracks are one of the most common forms of mechanical damage of rolling surface of bearing rings, rolling mills, as well as railroad wheels and rails in the contact zone. Crack spreading causes contact-

\begin{abstract}
:
An effective theoretical-experimental approach to evaluation of wheel steels resistance to contactfatigue damage (spalling) formation by pitting mechanism is proposed. On the base of the results of experimental studies and calculations, the contact-fatigue life curve of high-tempered $65 \Gamma$ steel is built. The results are similar and compared to a model low-tempered $75 X \Gamma C T$ steel.
\end{abstract}

fatigue damages on the surface, in particular spalls. In the most common cases, spalls are being formed from cracks that initiate and grow from the surface to the depth of material, by pitting mechanism. After the accumulation of critical amount of spalls the component requires expensive repair. For instance, railway wheels need to be dismantled with subsequent surfacing and machining of the rolling surface. Therefore, nowadays the rolling contact fatigue life of the wheel steels is determined by the

\footnotetext{
* Corresponding author. Tel.: +380672823572

E-mail address: kulykvolodymyrvolodymyrovych@gmail.com
} 
number of contact loading cycles till the moment of surface damage initiation. When the critical damage occurres the testing device indicates this commonly by the vibration sensor and the experimental procedure is stopped automatically. However, a critical damage indicated by a testing device may have different features. It can be spall formation on the rolling surface of the model wheel, the long fatigue macrocrack initiation or system of many short cracks initiated on the entire rolling surface [6-10]. All of these types of damages occur at the laboratory rolling contact fatigue conditions, and testing if a device sensor is not capable to separate these types. Thus, it is very complicated to estimate the resistance of several compared steels for the one type of critical damage, because a large scattering of the experimental data in such studies often leads to contradictory results [6]. In some cases, the same value of number of loading cycles is obtained for different steels untill the surface damage occurs. In other cases, different values of number of cycles are obtained for several samples of the same steel. Despite that, these results are used to make conclusions concerning the workability at contact fatigue conditions, as long-term performance of steel ensuring structure rigidity and reliability under cyclic loading (bearing balls, railway wheels and rails, rollers, gears, e. g.). That is a main reason why the new alternative theoretical and experimental approaches that would not require complex fatigue testing of model wheels are needed.

Based on literature survey [11-13], we can formulate the main stages of the further research as following:

- Building the fatigue crack growth rate curves of steels at normal tension and transverse shear and cyclic crack growth resistance characteristics determination.

- Choosing the parameters of contact interaction of rolling bodies for theoretical studies taking into account the real service conditions.

- Determination of the fatigue crack growth trajectory at spall formation, as well as the crack size and number of cycles till separation of material fragment from the surface of rolling body.

\section{Investigation techniques}

Research was conducted on $65 \Gamma$ steel (analogues are 1066, 1566 Ck67, 080A67, 65Mn, 65G steels contained $\sim 0.65 \% \mathrm{C}$ ), because it has a chemical composition and structure very close to all-rolled railway wheels steels $[14,15]$. Before the fatigue crack growth rates testing, $65 \Gamma$ steel samples were subjected to heat treatment consisting of quenching from $820^{\circ} \mathrm{C}$ in oil and subsequent tempering at $650^{\circ} \mathrm{C}$ for 1 hour. During this classical heat treatment the diffusion process of martensite disintegration and carbide transformation occurs and causes formation of high-tempered martensite consisting of the plate-globular cementite formations of irregular shape that fill ferritic matrix. It should be noted that the cementite plates in structures after hardening and high tempering are similar in appearance to granular pearlite and are characterized by higher dispersion caused by increasing their sphericity, an unlike oblong shape of cementite plates in cases when tempering is performed at lower temperatures [12]. For performing a fatigue test and determination of fatigue crack growth resistance at normal tension standard compact specimens (Fig. 1) with edge crack $\left(H=54.0 \mathrm{~mm} ; b_{1}=56.3 \mathrm{~mm} ; b=45.0 \mathrm{~mm}\right.$; $2 d=24.8 \mathrm{~mm} ; D=11.0 \mathrm{~mm} ; t=10.0 \mathrm{~mm} ; c=1.4$ $\mathrm{mm} ; h=11.0 \mathrm{~mm}$ ) were tested using a hydraulic testing machine Heckert EUS-20 at stress ratio $R=0.1$ and frequency $15 \mathrm{~Hz}$ according to the recommendations [16]. The fatigue testing at transverse shear were performed on I-beam specimens (Fig. 2) with the edge longitudinal crack $\left(L_{1}=180.0 \mathrm{~mm} ; \quad H_{1}=32.0 \mathrm{~mm} ; \quad r=20.0 \mathrm{~mm}\right.$; $L=110.2 \mathrm{~mm} ; W=27.0 \mathrm{~mm} ; D=6.0 \mathrm{~mm} ; H=27.8$ $\mathrm{mm} ; T=9.6 \mathrm{~mm} ; b_{1}=87.8 \mathrm{~mm} ; b=72.0 \mathrm{~mm}$; $2 d=15.9 \mathrm{~mm} ; c=1.4 \mathrm{~mm} ; t=3.2 \mathrm{~mm} ; t_{0}=1.1 \mathrm{~mm}$; $h=25.2 \mathrm{~mm}$ ) using an original testing setup YBB500 at stress ratio $R=-1$ and frequency $12 \mathrm{~Hz}$ according to standard [17].
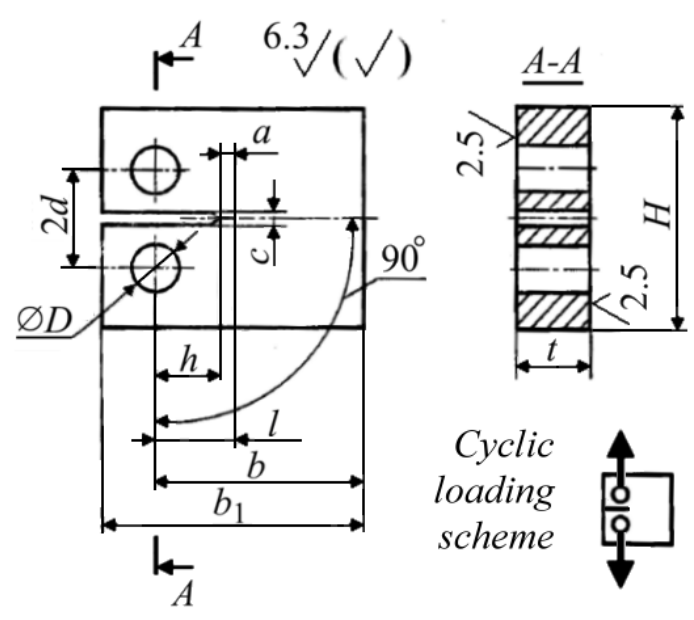

Figure 1. Compact specimen for testing under cyclic normal tension 
For the crack growth measurement an optical cathetometer B-630 equipped with digital camera ToupTech UCMOS 10000KPA was used. The crack growth rate was calculated as $v=\Delta a / \Delta N$, where $\Delta a$ is a crack length increment during $\Delta N$ loading cycles. The stress intensity factor range $\Delta K$ was determined by dependence $\Delta K=(1-R) K_{\max }$. So, respectively, at normal tension $\Delta K_{\mathrm{I}}=0.9 K_{\mathrm{I} \max }$, and in the case of transverse shear $\Delta K_{\text {II }}=2 K_{\text {II max }}$. Maximal stress intensity factor value $K_{\max }$ in a load cycle under normal tension for relative fatigue crack lengths $0.45 \leq l / b \leq 0.55$ was calculated by the following equation:

$$
K_{\text {Imax }}=\frac{P_{\max }}{t \sqrt{b}} Y
$$

In this equation $P_{\max }$ - maximum force in a load cycle, $t$ - specimen thickness, $b$ - basic dimension, and $Y$ - function calculated by:

$$
Y=13.74\left[1-3.38 \frac{l}{b}+5.572\left(\frac{l}{b}\right)^{2}\right]
$$

where $l$ - total crack length.

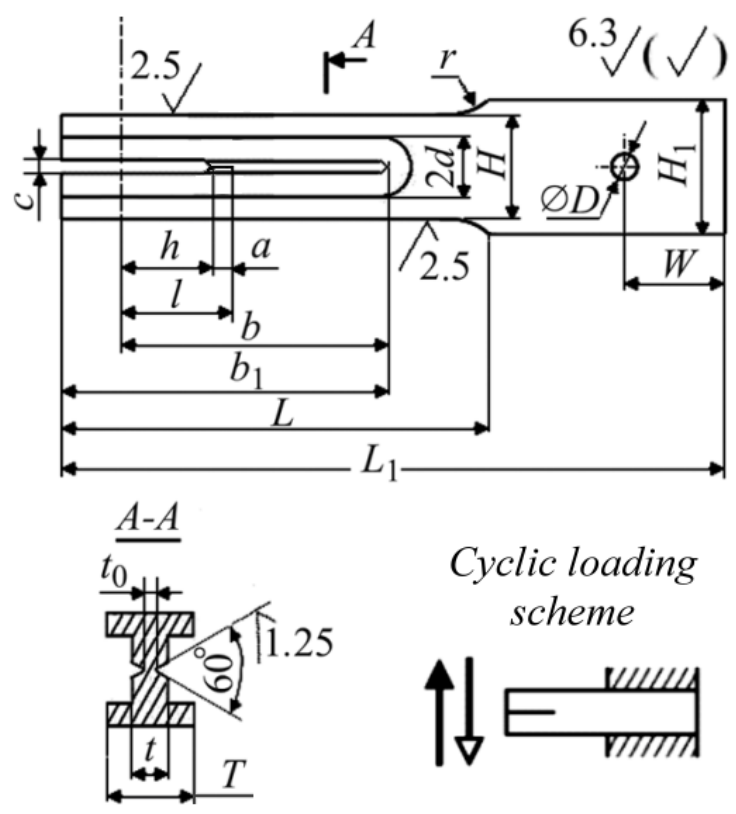

Figure 2. I-beam specimen for testing under cyclic transverse shear

For a transverse shear case $K_{\max }$ value was calculated by the equation:

$$
K_{\text {IImax }}=\frac{P_{\max }}{t_{0} \sqrt{H}} Y
$$

Here are $P_{\max }$ - maximum force in symmetric load cycle, $t_{0}$ - specimen thickness, and $Y$ - function calculated by:

$$
Y=0.22+6.29 \frac{l}{b}-f_{c}\left(1.2 \frac{l}{b}+1.34\right),
$$

where $l$ - total crack length, $b$ - basic dimension $f_{c}-$ crack faces friction factor. To establish crack faces friction factor $f_{c}$ at the transverse shear fragments of fractured I-beam specimen containing crack faces were cut out and tested as a friction pair according to Amontons Coulomb's law using the original device and technique described in [18]. On the base of test results, the fatigue crack growth rate curves in logarithmic coordinates $\Delta K\left(\Delta K_{\mathrm{I}}\right.$ for normal tension and $\Delta K_{\text {II }}$ for transverse shear) vs. $v$ were built by approximation of the experimental data points with S-lines. These graphical dependencies were used for normal tension and transverse shear to determine fatigue crack growth resistance characteristics, namely fatigue threshold $\Delta K_{\text {th }}$ and fracture toughness $\Delta K_{\mathrm{fc}}$, as the values of $\Delta K$ for crack growth rate $V=10^{-10}$ and $10^{-4} \mathrm{~m} /$ cycle, respectively. For analytical description of the fatigue crack growth rate curves Yarema-Mykytyshyn equation [19] was used:

$$
v(\Delta K)=v_{0}\left(\frac{\Delta K-\Delta K_{t h}}{\Delta K_{f c}-\Delta K}\right)^{q}
$$

where $v$ - crack growth rate, $v_{0}$ and $q$ - parameters indicating the symmetry center and the inclination angle of the middle section of the S-curve respectively.

For theoretical study the known mathematical model [13] was used. According to this model, the damaged body is modeled as an elastic half-plane with an edge crack, and the action of counterbody as normal contact pressure with the Hertz force distribution. The residual life of damaged body is estimated by the period of the crack growth from initiation to critical length, that is, by the number of loading cycles $N_{\mathrm{g}}$. Since the crack at different stages propagates by different modes, then $N_{\mathrm{g}}=N_{\mathrm{g}}^{(\tau)}+$ $N_{\mathrm{g}}{ }^{(\sigma)}$, where: 


$$
\begin{aligned}
& N_{\mathrm{g}}{ }^{(\tau)}=\int_{l_{0}{ }^{(\tau)}}^{l_{c}^{(\tau)}} v^{-1}\left(\Delta K_{\mathrm{II} \theta}(l), C_{j}{ }^{(\tau)}\right) d l \\
& N_{\mathrm{g}}{ }^{(\sigma)}=\int_{l_{0}{ }^{(\sigma)}}^{l_{c}{ }^{(\sigma)}} v^{-1}\left(\Delta K_{\mathrm{I} \theta}(l), C_{j}{ }^{(\sigma)}\right) d l
\end{aligned}
$$

Here $\Delta K_{\mathrm{m} \theta}=\max K_{\mathrm{m} \theta}-\min K_{\mathrm{m} \theta}(m=\mathrm{I}, \mathrm{II}), N_{\mathrm{g}}{ }^{(\tau)}$ and $N_{\mathrm{g}}{ }^{(\sigma)}$ - is the fatigue life at the stage of crack propagation by modes of transverse shear and normal tension respectively; $l_{0}{ }^{(\tau)}, l_{\mathrm{c}}{ }^{(\tau)}=l_{0}{ }^{(\sigma)}, l_{\mathrm{c}}{ }^{(\sigma)}-$ initial and critical crack lengths; $v=d l / d N$ - crack growth rate; $l$ - crack length. The values of SIF $K_{\mathrm{I}}$ and $K_{\mathrm{II}}$ were determined by solution of the system of integral equations of the contact problem of elasticity theory; $C_{j}^{(\tau)}, C_{j}^{(\sigma)}(j=1,2, \ldots)$ - are constants, calculated on the basis of experimentally determined crack growth resistance characteristics.

To automate mathematical calculations and increase their ergonomics, a new original software for mathematical transformations was created. The following parameters characterizing the wheel-rail interaction were set in calculations (Fig. 3): contact pressure $p_{0}=1400 \ldots 2000 \mathrm{MPa}$, half-width of the contact spot $a^{*}=7 \mathrm{~mm}$; friction factor between bodies $f_{\mathrm{s}}=0.1$; angle of inclination of the initial shear crack $\beta=5 \pi / 6$; greased crack faces friction factor $f_{\mathrm{c}}=0.15$; normal uniform pressure on tension crack faces $p_{1}=0.1 p_{0}$.

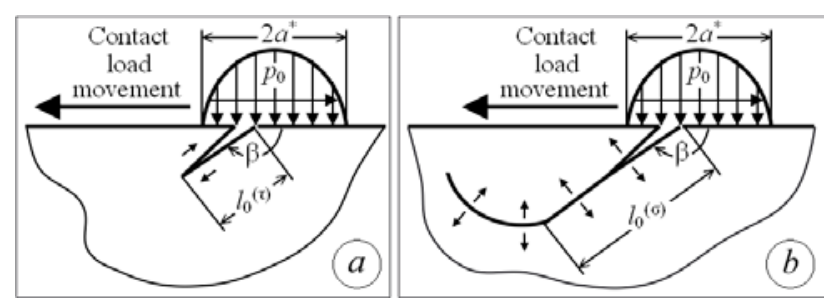

Figure 3. Calculation schemes for the stages of crack propagation at transverse shear (a) and normal tension (b)

Using a software, the residual fatigue life of steel was calculated on a basis of the above written integral equations, according to the generalized expression:

$$
N_{g}=\sum_{k=1}^{j_{c}} \Delta l_{k} v_{k}^{-1}\left[\Delta K(l), C_{j}\right]
$$

Here $j_{c}$ - the total number of crack propagation steps till critical length; $l_{k} i v_{k}$ - the crack length increment and the crack tip velocity at $k$-th step respectively.

\section{Results and discussion}

As it can be seen from the tests results (Fig. 4), the fatigue crack growth rate curves of $65 \Gamma$ steel shows the rate change at low- $\left(\Delta K_{\mathrm{I}}<15 \mathrm{MPa} \sqrt{\mathrm{m}}, \Delta K_{\mathrm{II}}<\right.$ $24 \mathrm{MPa} \sqrt{\mathrm{m}})$, middle- $\left(\Delta K_{\mathrm{I}}=15 \ldots 72 \mathrm{MPa} \sqrt{\mathrm{m}}, \Delta K_{\mathrm{II}}=\right.$ 24...116 $\mathrm{MPa} \sqrt{\mathrm{m}})$ and high-amplitude loading $\left(\Delta K_{\mathrm{I}}>72 \mathrm{MPa} \sqrt{\mathrm{m}}, \Delta K_{\mathrm{II}}>116 \mathrm{MPa} \sqrt{\mathrm{m}}\right)$ for both fracture modes. The middle sections of the curves lies within the crack growth rates range $v \approx 2 \cdot 10^{-8} \ldots$ $10^{-6} \mathrm{~m} /$ cycle for both fracture modes. For transverse shear mode we can see the greater scatter of points on this region of curve. In contrast, the normal tension of experimental points are much less scattered. This proofs that the fatigue crack growth at the transverse shear has intermittent feature that makes the process of approximation of the experimental points more complicated. The fatigue crack growth resistance characteristics obtained from the fatigue crack growth rate curves are represented in Table 1 . The obtained values correlate well with the known data [20].

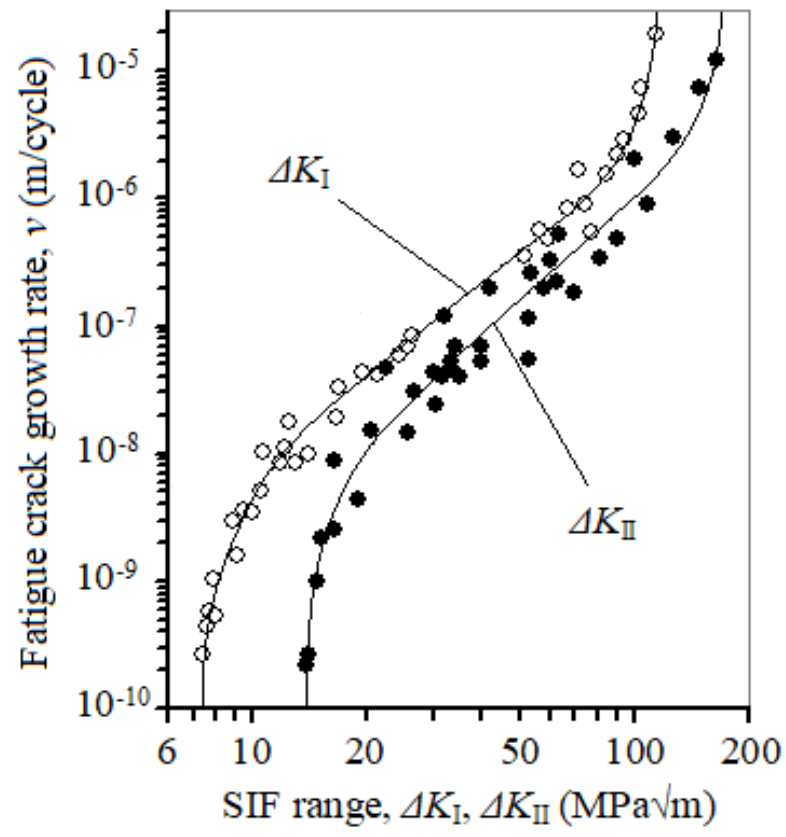

Figure 4. Fatigue crack growth rate curves of $65 \Gamma$ steel $\left(\sigma_{0.2}=830 \mathrm{MPa}\right)$ built considering crack faces friction 
As a result of the calculations based on theoretical model, it was found that the initial and critical lengths of the crack decrease with increasing contact pressure (Table 2). The same tendencies are observed for the spall size, characterized by width $a_{\mathrm{c}}$ and depth $b_{c}$. This leads to a decrease in loading cycles number at each stage of the fatigue crack growth. It should be noted that width of spall is $\sim 3$ times larger than spall depth. The estimation of $b_{\mathrm{c}} / a_{\mathrm{c}}$ ratio shows that the values correlate with the experimental study [21] of 30CrMoV9 steel on rolling contact fatigue well and exists in range $0.34 \ldots 0.37$.

Table 1. Crack growth resistance characteristics of high-tempered $65 \Gamma$ steel

\begin{tabular}{|c|c|c|c|c|}
\hline \multirow{3}{*}{$\begin{array}{l}\text { Fracture } \\
\text { mode }\end{array}$} & Threshold SIF range & Critical SIF range & \multicolumn{2}{|c|}{$\begin{array}{l}\text { Parameters of the Yarema- } \\
\text { Mykytyshyn equation [19] }\end{array}$} \\
\hline & $\Delta K_{\text {th }}$ & $\Delta K_{\mathrm{fc}}$ & \multirow{2}{*}{$\frac{v_{0}}{\mathrm{~m} / \text { cycle }}$} & \multirow{2}{*}{$q$} \\
\hline & \multicolumn{2}{|c|}{$\mathrm{MPa} \sqrt{\mathrm{m}}$} & & \\
\hline Normal tension & 7.4 & 118 & $6.4 \cdot 10^{-7}$ & 1.31 \\
\hline Transverse shear & 13.8 & 170 & $7.1 \cdot 10^{-7}$ & 1.28 \\
\hline
\end{tabular}

Table 2. The influence of contact pressure on the spall shape (see Fig. 5)

\begin{tabular}{|c|c|c|c|c|c|c|}
\hline $\begin{array}{c}\text { Contact } \\
\text { pressure }\end{array}$ & $\begin{array}{c}\text { Initial length } \\
\text { of shear crack }\end{array}$ & $\begin{array}{c}\text { Initial length } \\
\text { of tension crack }\end{array}$ & $\begin{array}{c}\text { Width } \\
\text { of spall }\end{array}$ & $\begin{array}{c}\text { Depth } \\
\text { of spall }\end{array}$ & $\begin{array}{c}\text { Life } \\
\text { at shear } \\
\text { stage }\end{array}$ & $\begin{array}{c}\text { Life } \\
\text { at tension } \\
\text { stage }\end{array}$ \\
\hline$p_{0}$ & $l_{0}{ }^{(\tau)}$ & $l_{0}^{(\sigma)}$ & $a_{\mathrm{c}}$ & $b_{\mathrm{c}}$ & $N_{\mathrm{g}}{ }^{(\tau)}$ & $N_{\mathrm{g}}{ }^{(\sigma)}$ \\
\hline $\mathrm{MPa}$ & \multicolumn{5}{|c|}{$\mathrm{mm}$} & \multicolumn{2}{|c|}{ cycles } \\
\hline 1400 & 0.971 & 3.241 & 4.654 & 1.620 & 605746 & 2498049 \\
\hline 1500 & 0.846 & 2.978 & 4.008 & 1.489 & 497151 & 2062515 \\
\hline 1600 & 0.750 & 2.730 & 3.756 & 1.365 & 466812 & 1905958 \\
\hline 1700 & 0.676 & 2.522 & 3.545 & 1.261 & 382351 & 1773384 \\
\hline 1800 & 0.627 & 2.346 & 3.298 & 1.173 & 313876 & 1633159 \\
\hline 1900 & 0.572 & 2.194 & 3.150 & 1.097 & 340671 & 1519763 \\
\hline 2000 & 0.516 & 2.061 & 3.021 & 1.030 & 313617 & 1434180 \\
\hline
\end{tabular}

The curve describing workability of hightempered $65 \Gamma$ steel at rolling contact fatigue conditions has a sloping descending appearance (Fig. 5), qualitatively similar to the model lowtempered steel 75ХГСТ [13]. However, it should be noted that fracture of $65 \Gamma$ steel requires much more loading cycles, which indicates its higher crack growth resistance at contact fatigue than

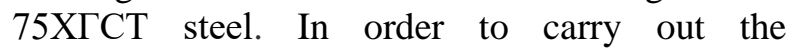
quantitative analysis, the relative fatigue life parameter $\Omega$ was introduced, representing the ratio of the number of cycles till spall formation for the investigated steel to corresponding number for the model steel $\Omega=N_{\mathrm{g}}{ }^{(65 \Gamma)} / N_{\mathrm{g}}{ }^{(75 Х Г С Т)}$. From the bar charts with various contact pressures (Fig. 6), it can be seen that at $p_{0}=1800 \mathrm{MPa}$ life of $65 \Gamma$

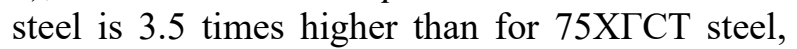
and at $p_{0}=1400 \mathrm{MPa}-$ almost 4.5 times.

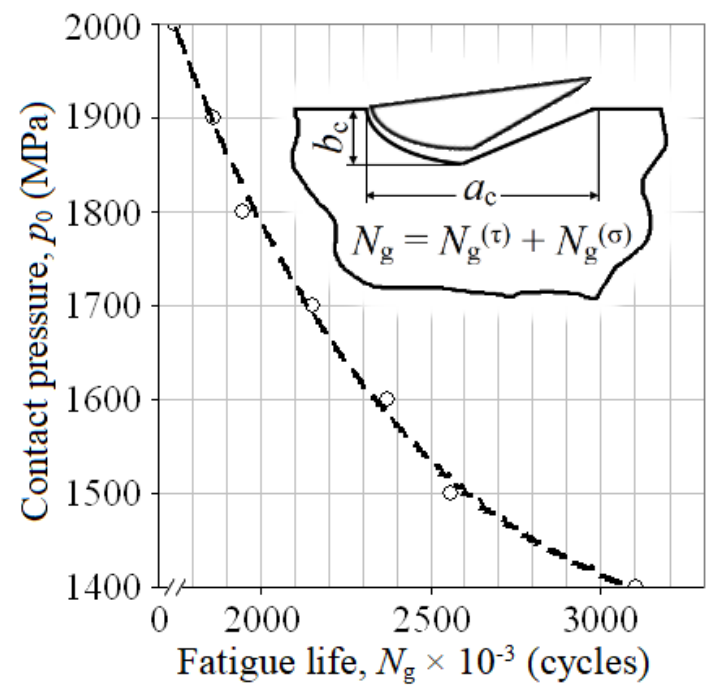

Figure 5. Residual life curve of $65 \Gamma$ steel based on the criterion of the spall formation 


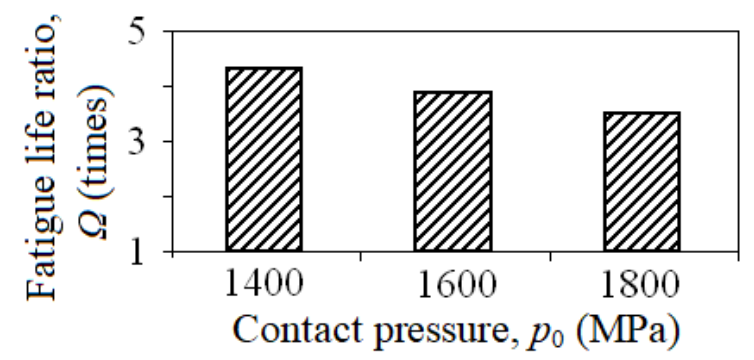

Figure 6. Fatigue life ratios of compared steels at different contact pressures

\section{Conclusion}

The new effective theoretical-experimental approach to evaluation of the contact-fatigue damage (spalling) resistance of steels for railway wheels is proposed. This approach doesn't require the difficult massive fatigue testing of model wheels and is simple in practical engineering usage.

According to the first stage of the proposed approach, the experimental study of the fatigue crack growth rates of high-tempered 65 $\Gamma$ steel for different modes (normal tension and transverse shearing) of fracture is completed and basic characteristics of the fatigue crack growth resistance are firstly obtained as YaremaMykytyshyn equation parameters needed for full description of experimental curves.

Using the presented approach, it is established that the resistance of high-tempered $65 \Gamma$ steel to spall formation by pitting mechanism is much higher (more than 3 times) in comparison to the

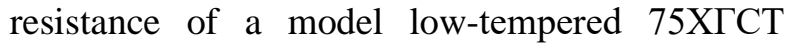
steel. This indicates its better workability, for instance, as a material for all-rolled railway wheels working at the contact fatigue conditions.

\section{Acknowledgment}

This research was supported by "Problems of lifetime and exploitation safety of structures, constructions and machines" target complex program of the National Academy of Sciences of Ukraine. We thank our colleagues from Department of Strength and Durability of Structures under Complex Loading, Karpenko Physico-Mechanical Institute who provided insight and expertise that greatly assisted the investigation represented in this paper. We would also like to show our gratitude to doctor
Oleksandra Datsyshyn for sharing her pearls of wisdom with us and strong cooperation in rolling contact fatigue topic during the course of this investigation.

\section{References}

[1] Sadeghi, F., Jalalahmadi, B., Slack, T. S., Raje, N., Arakere, N. K.: A Review of Rolling Contact Fatigue, Journal of Tribology, 131 (2009), 4, 041403.

[2] Deng, S., Hua, L., Han, X., Huang, S.: Investigation of rolling contact fatigue cracks in ball bearings, International Journal of Fracture, 188 (2014), 1, 71-78.

[3] Aslantas, K., Tasgetiren, S.: Edge spalling formation in a plate due to moving compressive load, Turkish Journal of Engineering \& Environmental Sciences, 27 (2003), 5, 333-338.

[4] Bormetti, E., Donzella, G., Mazzu, A.: Surface and subsurface cracks in rolling contact fatigue of hardened components, Tribology Transactions, 45 (2002), 3, 274283.

[5] Ko, P. L., Iyer, S. S., Vaughan, H., Gadala M.: Finite element modelling of crack growth and wear particle formation in sliding contact, Wear, 251 (2001), 1-12, 1265-1278.

[6] Beynon, J. H., Garnham, J. E., Sawley, K. J.: Rolling contact fatigue of three pearlitic rail steels, Wear, 192 (1996), 1-2, 94-111.

[7] Clayton, P., Su, X.: Surface initiated fatigue of pearlitic and bainitic steels under water lubricated rolling/sliding contact, Wear, 200 (1996), 1-2, 63-73.

[8] Tyfour, W. R., Beynon, J. H., Kapoor, A.: Deterioration of rolling contact fatigue life of pearlitic rail steel due to dry-wet rollingsliding line contact, Wear, 197 (1996), 1-2, 255-265.

[9] Zhong, W., Hu, J. J., Shen, P., Wang, C. Y., Lius, Q. Y.: Experimental investigation between rolling contact fatigue and wear of high-speed and heavy-haul railway and selection of rail material, Wear, 271 (2011), 9-10, 2485-2493.

[10] Miyashita, Y., Yoshimura, Y., Xu, J., Horikoshi, M., Mutoh, Y.: Subsurface crack propagation in rolling contact fatigue of sintered alloy, International Journal Series A 
Solid Mechanics and Material Engineering, 46 (2003), 3, 341-347.

[11] Ostash, O. P., Panasyuk, V. V., Andreiko, I. M., Chepil' R. V., Kulyk, V. V., Vira, V. V.: Methods for the construction of the diagrams of fatigue crack-growth rate of materials, Materials Science, 43 (2007), 4, 473-491.

[12] Ivanyts'kyi, Ya. L., Lenkovs'kyi, T. M., Verhun, I. A., Shtayura, S. T.: Investigation of the Kinetics of Fatigue Macrocracks Under Transverse Shear, Materials Science, 52 (2016), 3, 349-356.

[13] Datsyshyn, O. P., Panasyuk, V. V., Glazov A. Yu.: The model of the residual life time estimation of trybojoint elements by formation criteria of the typical contact fatigue damages, International Journal of Fatigue, 83 (2016), 2, 300-312.

[14] State Standard GOST 10791-2011, All-rolled wheels, Specifications, Standartinform, Moscow, 2011, (in Russian).

[15] Ostash, O. P., Andreiko, I. M., Kulyk, V. V., Vavrukh, V. I.: Influence of braking on the microstructure and mechanical behavior of railroad wheel steels, Materials Science, 48 (2013), 5, 569-574.

[16] Methodical guidelines RD 50-345-82, Methods for mechanical tests of metals, Determination of the characteristics of crack-growth resistance (fracture toughness) under cyclic loading, Izd. Standartov, Moscow, 1983, (in Russian).
[17] State Standard DSTU 8601:2015. Calculation and strength tests, The method for determining crack growth resistance characteristics under transverse shear of metals at room temperature, DP “UkrNDNC”, Kyiv, 2016, (in Ukrainian).

[18] Ivanytskyj, Ya. L., Lenkovskiy, T. M., Molkov, Yu. V., Kulyk, V. V., Duriagina, Z. A.: Influence of $65 G$ steel microstructure on crack faces friction factor under mode II fatigue fracture, Archives of Materials Science and Engineering, 82 (2016), 2, 49-56.

[19] Yarema, S. Ya., Mikitishin, S. I.: Analytical description of the fatigue-failure diagram of materials, Soviet Materials Science, 11 (1976), 6, 660-666.

[20] Kulyk, V. V., Lenkovs’kyi, T. M., Ostash, O. P.: Mode I and Mode II Cyclic Crack Resistance of Wheel Steel, Strength of Materials, 49 (2017), 2, 256-262.

[21] Górecki, K., Cios, G., Stępień, M., Marzec, M., Wieczerzak, K.: Analysis of pitting wear phenomena in 30CrMoV9 steel samples with Si-DLC coating, Metal 2015: 24th International Conference on Metallurgy and Materials (2015). 